\section{Fever after subarachnoid hemorrhage}

In this study of 353 patients with subarachnoid hemorrhage, Fernandez et al. found that fever was strongly predicted by the presence of poor clinical grade and intraventricular hemorrhage, and associated significantly with increased mortality, functional disability, and cognitive impairment at 3 months.

see page 1013

There is an accompanying editorial by Geoffrey S.F. Ling.

see page 973

\section{Leukoaraiosis and intracerebral hemorrhage in acute ischemic stroke}

Palumbo et al. studied whether the presence of leukoaraiosis and multiple lacunes on baseline CT scan is associated with symptomatic intracerebral hemorrhage (sICH) after thrombolysis in acute ischemic stroke. With an overall sICH rate of $3.5 \%$ observed in 820 patients, a significant increase on the risk of $\mathrm{sICH}$ was observed in patients with radiologic evidence of small vessels disease, reaching $10 \%$ in those with multilacunar state.

see page 1020

\section{Hereditary hemochromatosis} genotypes and stroke

Ellervik et al. conducted a prospective study of 9,178 individuals from the Danish general population followed for 24 years, during which 393 developed ischemic stroke. Hereditary hemochromatosis H63D homozygosity predicted a two- to threefold risk of ischemic stroke.

see page 1025

\section{Inflammatory biomarkers and brain volume}

Jefferson et al. found that elevated inflammatory markers were associated with greater brain atrophy in participants free from clinical dementia and stroke. Though the pathophysiology of these findings is unclear, further research is merited to better understand the role of inflammation in brain atrophy.

see page 1032

\section{Motor cortical GABAergic inhibition is normal in DYT5}

Hanajima et al. studied the motor cortical inhibitory function using paired pulse TMS in nine patients with Segawa disease (DYT5). Motor cortical inhibition was intact in Segawa disease. These findings differ from previous results in focal dystonia suggesting that alternate mechanisms are responsive for dystonia in Segawa disease as compared with other dystonias.

see page 1039

\section{rTMS to treat spasticity in MS patients}

Centonze et al. studied repetitive transcranial magnetic stimulation in patients with MS with lower limb spasticity. Five $\mathrm{Hz}$ rTMS decreased H/M amplitude ratio of the soleus H-reflex and increased corticospinal excitability. When the treatment was continued for two consecutive weeks, a durable improvement of spasticity was also observed.

see page 1045

\section{Quality of life in muscle disease}

Vincent et al. described the development of a unique muscle disease specific QoL measure which would be more relevant to those with muscle disease than existing generic QoL measures. This questionnaire is designed for clinical as well as research use.

see page 1051

\section{ALS and mental health: Cultural differences?}

In a cross-cultural study of patients with ALS near the end of life, Albert et al. found that American patients reported less distress than Israeli patients. There may be important cultural effects on patient willingness to report negative states or accept descriptions of mental health.

see page 1058

\section{Bradyphrenia in PD and hypofunctioning of the striatum}

Sawamoto et al. demonstrated that the slowing of mental performance in PD was related to the hypofunctioning of the anterior striatum in studies using H2150 PET. The finding also indicates a role of the basal ganglia in nonmotor cognitive functions.

see page 1062 


\title{
Neurology
}

\author{
March 27 Highlights \\ Neurology 2007;68;972 \\ DOI 10.1212/01.wnl.0000259399.50861.92
}

This information is current as of March 26, 2007

\section{Updated Information \&} Services

Permissions \& Licensing

Reprints including high resolution figures, can be found at: http://n.neurology.org/content/68/13/972.full

Information about reproducing this article in parts (figures,tables) or in its entirety can be found online at:

http://www.neurology.org/about/about_the_journal\#permissions

Information about ordering reprints can be found online:

http://n.neurology.org/subscribers/advertise

Neurology ${ }^{\circledR}$ is the official journal of the American Academy of Neurology. Published continuously since 1951, it is now a weekly with 48 issues per year. Copyright . All rights reserved. Print ISSN: 0028-3878. Online ISSN: 1526-632X.

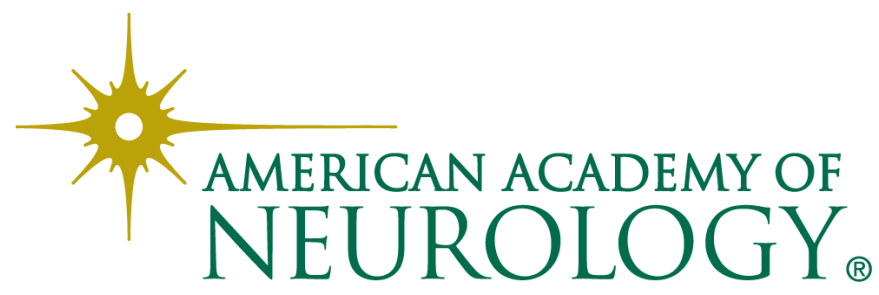

